Annales Geophysicae (2001) 19: 159-170 (C) European Geophysical Society 2001

\title{
ULF waves with drift resonance and drift-bounce resonance energy sources as observed in artificially-induced HF radar backscatter
}

\author{
T. K. Yeoman and D. M. Wright \\ Department of Physics and Astronomy, University of Leicester, University Road, Leicester LE1 7RH, UK
}

Received: 3 July 2000 - Revised: 7 December 2000 - Accepted: 18 December 2000

\begin{abstract}
HF radar backscatter which has been artificiallyinduced by a high power RF facility such as the EISCAT heater at Troms $\varnothing$ has been demonstrated to provide ionospheric electric field data of unprecedented temporal resolution and accuracy. Here such data are used to investigate ULF wave processes observed by the CUTLASS HF radars. Within a short period of time during a single four hour experiment three distinct wave types are observed with differing periods, and latitudinal and longitudinal phase evolution. Combining information from the three waves allows them to be divided into those with a large-scale nature, driven externally to the magnetosphere, and those with small azimuthal scale lengths, driven by wave-particle interactions. Furthermore, the nature of the wave-particle interactions for two distinct small-scale waves is revealed, with one wave interpreted as being driven by a drift resonance process and the other by a drift-bounce resonance interaction. Both of these mechanisms with $m \approx-35$ and proton energies of $35-45 \mathrm{keV}$ appear to be viable wave energy sources in the postnoon sector.
\end{abstract}

Key words. Ionosphere (active experiments; wave-particle interactions) - Magnetospheric physics (MHD waves and instabilities).

\section{Introduction}

In general, magnetospheric Ultra Low Frequency (ULF) waves which have an energy source external to the Earth, such as an impulse in the solar wind, solar wind buffeting, or the Kelvin-Helmholtz instability on the magnetopause, are characterised by small effective azimuthal wavenumbers $m$, (or equivalently a large scale size in the azimuthal direction). Conversely, it is now widely accepted that an energy source for small-scale, high- $m$ ULF waves exists in drifting energetic particle fluxes through drift and drift-bounce resonance interactions. Such high- $m$ waves are a topic of considerable

Correspondence to: T. K. Yeoman

(tim.yeoman@ion.le.ac.uk) importance in both theoretical and experimental studies at present. Energetic particles entering the Earth's inner magnetosphere from the magnetotail will experience gradientcurvature drift and thus move around the Earth, constituting part of the global ring current. The drifting particles can drive MHD wave modes through wave-particle interactions, leading to perturbations in the electric and magnetic fields in the magnetosphere and ionosphere when free energy is available to the wave. It has been suggested (e.g. Southwood, 1976; Hughes et al., 1978) that the part of the ion distribution function which is able to feed energy into the wave is when $\partial f / \partial W>0$, where $f$ is the ion distribution function and $W$ is the energy. Such non-Maxwellian ion distribution functions can be created quite commonly by naturally-occurring processes in the magnetosphere, such as substorm-associated particle injections. Subsequent to such an injection the ions will gradient-curvature drift westwards, where they will on occasion match the local drift-bounce resonance condition (Southwood et al., 1969),

$\omega_{\text {wave }}-m_{\text {wave }} \omega_{\text {drift }}=N \omega_{\text {bounce }}$

where $N$ is an integer (usually \pm 1 ) and $\omega_{\text {wave }}, \omega_{\text {bounce, }}$, and $\omega_{\text {drift }}$ are the angular frequencies of the wave, the proton bounce, and the proton azimuthal drift, respectively. Such wave-particle interactions are a process of fundamental importance in collisionless astrophysical plasmas.

The ionosphere modifies the magnetospheric ULF wave signature, leading to rotation and attenuation of the wave magnetic signature detected on the ground (e.g. Hughes and Southwood, 1976; Hughes, 1983). This attenuation of the pulsation magnetic perturbation below the ionosphere is proportional to $\exp (-k z)$ (e.g. Hughes and Southwood, 1976) where $k$ is the field perpendicular component of the wave number and $z$ is the E-region height. It is thus clear that ground magnetometer data is far from optimal for the study of high- $m$ ULF waves, and that direct observation in the ionosphere or magnetosphere is usually required. In particular, two categories of particle-driven waves have been intensively studied with ground-based data: storm time pulsations and 
giant 'Pg' waves, which are dusk and dawn sector phenomena, respectively.

Storm time Pc5 pulsations have been seen in STARE (the Scandinavian Twin Auroral Radar Experiment; Greenwald et al., 1978) data (Allan et al., 1982, 1983). They are compressional waves of high $m$ number $(m=-20 \ldots-80$; here negative $m$ is taken to represent westward phase propagation) and frequency in the Pc5 range $(1.7-6.7 \mathrm{mHz})$ which are associated with a drift resonance source mechanism. Drift resonance involves fundamental wave modes, with the electric field symmetric about the equator (i.e. an equatorial electric field antinode). Storm-time Pc5s are observed in the dusk sector during magnetically disturbed intervals. Similar waves, but with an equatorward phase motion, have been seen in SABRE (the Sweden And Britain auroral Radar Experiment; Nielsen et al., 1983) and BARS (Bistatic Auroral Radar System; McNamara et al., 1983) coherent radar systems in the dusk sector by Yeoman et al. (1992) and Grant et al. (1992) respectively.

The second class of particle driven ULF waves of interest are giant 'Pg' pulsations which have been observed on the ground as well as by orbiting satellites at times when geomagnetic conditions are quiet. Pgs are an example of a particle-driven ULF wave which may be studied with groundbased magnetometers. Chisham and Orr (1991) presented a statistical study of 34 of these events observed on the EISCAT magnetometer cross network in northern Scandinavia. They found a peak in occurrence of these waves in the dawn/ prenoon sector and no events were observed in the afternoon. The average value of the azimuthal wave number was $\sim-26$ for the 34 events. Pgs have been related to drift-bounce resonance mechanisms with both symmetric (e.g. Takahashi et al., 1992) and antisymmetric (e.g. Chisham and Orr, 1991) wave modes, and the wave-particle interaction responsible for their generation thus remains controversial.

Recent results from DOPE (the DOppler Pulsation Experiment; Wright et al., 1997) at Troms $\varnothing$ in northern Norway have demonstrated the existence of populations of high- $m$ waves in both the morning and afternoon sectors (Yeoman et al., 2000). In this case the morning sector waves were the most populous, and had $m$-numbers in the order of 100 , high enough to screen the waves completely from ground magnetometers. The structure and occurrence of such particledriven waves have been studied by a number of authors in the magnetosphere with in situ spacecraft data, for both case studies (e.g. Hughes et al., 1979; Takahashi et al., 1990) and statistically (e.g. Kokubun, 1985; Takahashi et al., 1985; Anderson et al., 1990; Woch et al., 1990; Engebretson et al., 1992; Lessard et al., 1999). These studies are largely consistent with the ground-based results, identifying a strong population of particle-driven waves in the dusk sector. Events are also detected near dawn however, and a variety of waveparticle interaction modes have been invoked. In this paper, the HF radar artificial backscatter technique is used to provide a dataset for the study of particle-driven ULF waves of both symmetric and antisymmetric modes in the postnoon sector.

\section{Instrumentation}

The data presented here result from the generation of artificial ionospheric HF coherent backscatter. It is well known that the EISCAT Heating facility at Troms $\varnothing$, Norway (Rietveld et al., 1993) is capable of generating artificial fieldaligned irregularities using high power HF radio waves (e.g. Robinson, 1989). These irregularities are detectable by both incoherent and coherent scatter radars (e.g. Robinson et al., 1997). It is possible, given favourable ionospheric conditions, to modify the magnetosphere-ionosphere coupling conditions with facilities such as the Troms $\varnothing$ heater. Typically such experiments use modulated $\mathrm{E}$ region electrojet heating (e.g. Robinson et al., 2000). The present study involves unmodulated $\mathrm{F}$ region heating during quiet magnetospheric conditions, with the main electrojet currents lying far north of Troms $\emptyset$. The action of the heater is thus restricted to increasing the backscatter cross-section which the $\mathrm{F}$ region ionosphere offers to HF coherent radars. The CUTLASS (Cooperative UK Twin Located Auroral Sounding System) radar is an HF coherent backscatter radar system located at Hankasalmi, Finland and Pykkvibær, Iceland, and forms part of the SuperDARN array (Greenwald et al., 1995). CUTLASS is ideally situated for making observations of the heated volume over Troms $\varnothing$ (e.g. Bond et al., 1997; Eglitis et al., 1998), as shown schematically in Fig. 1a. Here data is presented from the SP-UK-OUCH (Observations of ULF waves with CUTLASS and the Heater; Wright and Yeoman, 1999b) experiment. In this experiment the CUTLASS radars run in a high temporal and spatial resolution mode, with Hankasalmi running a 6-beam scan (scanning beams 7 through to 2, inclusive) with an integration time of $1 \mathrm{~s}$, whilst Pykkvibær runs a 3-beam scan (beams 13-15) with a $2 \mathrm{~s}$ integration period. Thus, both radars produce data with a temporal resolution of $6 \mathrm{~s}$ and both run in a high spatial resolution mode, with each radar having 75 range gates of $15 \mathrm{~km}$ length, centred on the heated volume at Troms $\varnothing$. The EISCAT heater was in continuous operation at $50 \%$ power (using $6 \times 80 \mathrm{~kW}$ transmitters, an ERP of $\sim 130 \mathrm{MW}$ ), at a frequency of $\approx 4 \mathrm{MHz}$ for 4-hour intervals. The heater produces artificial electron density irregularities in the $\mathrm{F}$ region ionosphere, which act as targets for the HF radar. The artificial targets have been demonstrated to accurately track the natural ionospheric convection velocity, and the backscatter obtained is of very high power and very narrow spectral width. This allows a short integration time to be run on the radar, providing higher time resolution than is normally available. The narrow spectral widths also produce ionospheric electric field measurements of unprecedented accuracy (Yeoman et al., 1997; Wright and Yeoman, 1999a,b). Sample coherent and incoherent scatter spectra from natural and artificial irregularities are illustrated in Fig. 1b, c.

Data are also presented from the IMAGE (International Monitor for Auroral Geomagnetic Effects; Lühr, 1994) magnetometer station at Troms $\emptyset$ (TRO, location $69.7^{\circ} \mathrm{N}, 18.9^{\circ} \mathrm{E}$ geographic), which has a sampling interval of $10 \mathrm{~s}$. 
(a)

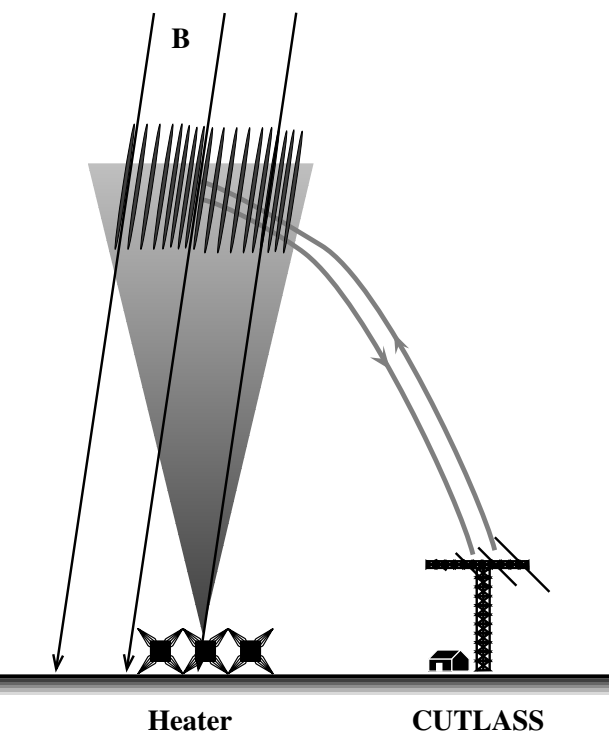

(b)

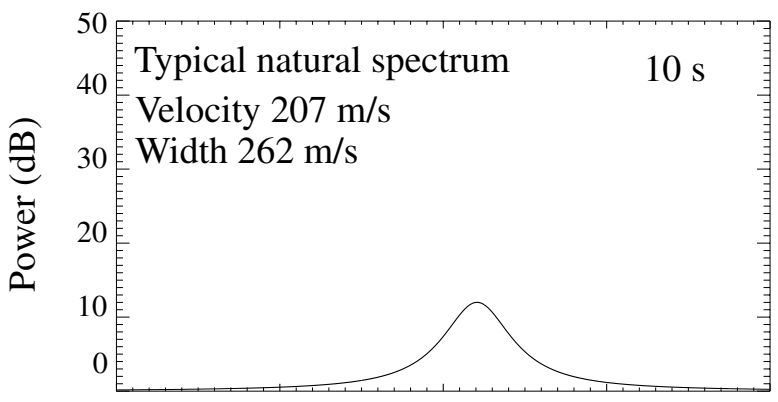

(c)

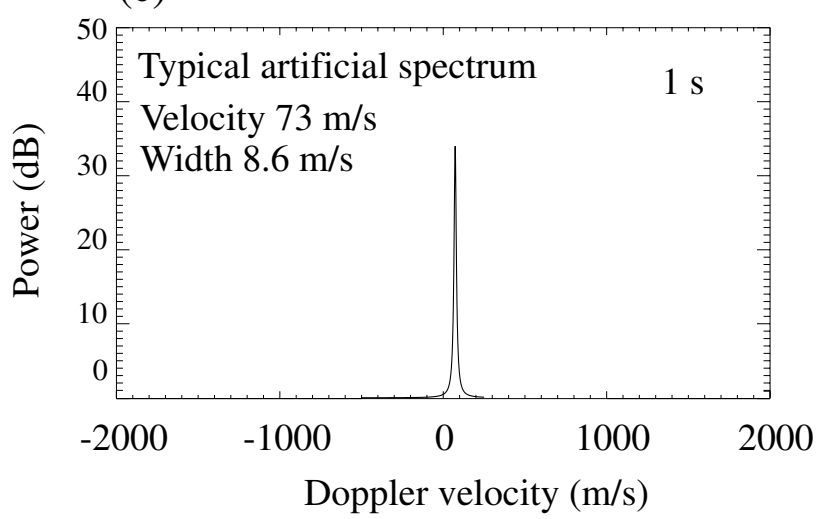

Fig. 1. (a) A schematic of the artificial backscatter experiment, SP-UK-OUCH. The Troms $\emptyset$ heater continuously heats the F region ionosphere, creating artificial ionospheric irregularities. These are detected by the CUTLASS radars, operating in a high temporal and spatial resolution mode. (b) A typical HF radar spectrum, obtained from fitting to the autocorrelation function of backscatter from natural $\mathrm{F}$ region irregularities after an integration period of $10 \mathrm{~s}$. (c) A similar spectrum, but this time obtained from a $1 \mathrm{~s}$ integration from a heated $F$ region. A narrower spectrum results, even from a shorter integration time.

\section{Observations}

During a four hour experimental run of the SP-UK-OUCH, the artificial backscatter technique has provided bistatic elec- tric field data during a complex period of wave activity. Unprecedented spatial, temporal and electric field resolution is achieved. Figure 2 presents a colour-coded representation (flow away from the radars (negative velocities) are colour coded red, with flow towards the radars (positive velocities) colour-coded blue) of the 1-o-s (line-of-sight) velocity measured by the CUTLASS Hankasalmi and Pykkvibær radars for several radar range gates over the complete four hour experiment. Figure 2a presents 1-o-s velocity from beam 5 of the Hankasalmi radar. This beam points roughly meridionally, and the data is plotted as a function of magnetic latitude. Figure $2 \mathrm{~b}$ presents 1-o-s velocity from beam 15 of the Pykkvibær radar, which is directed roughly azimuthally eastwards, as a function of magnetic longitude. A region of the high latitude ionosphere of roughly one degree in both latitude and longitude is illuminated by the EISCAT heater at Troms $\emptyset$. Complex and variable wave activity is clear in data from both radars. The wave characteristics in three different intervals are examined here: Interval 1, a period of largescale field line resonance activity; Interval 2, a period of low frequency, small-scale wave activity and Interval 3, a higher frequency, small-scale wave.

\subsection{Interval 1: 1230-1300 UT}

Interval 1 is presented in more detail in Fig. 3, which illustrates data from 1230-1300 UT. L-o-s velocity data only from Hankasalmi is presented, with the colour-coded velocities from a number of range gates plotted as a function of magnetic latitude in panel 3a. Panel $3 b$ presents the 1-o-s velocities in a simple timeseries format, whilst panels $3 \mathrm{c}, \mathrm{d}$ present $\mathrm{X}$ and $\mathrm{Y}$ component data from the underlying TRO magnetometer (which lies under range gate 32 ). The clearest wave signature in this interval is between 1250 and 1300 UT, although higher frequency waves are detectable before this. A poleward phase progression can be observed in Fig. $3 \mathrm{a}, \mathrm{b}$ and the longer period wave is also visible in both components of the Troms $\varnothing$ magnetograms. An analysis of the spectral power and phase of the wave is shown in Fig. 4. Figure 4a presents a Fourier power spectrum of the wave observed in the Hankasalmi velocity data from beam 5, range gate 28. The dominant Fourier component is at $5.7 \mathrm{mHz}$, although some evidence of higher frequency wave activity at $\sim 16 \mathrm{mHz}$ is also apparent. The magnetic latitude profile of Fourier power and phase deduced from the radar data at 5.7 $\mathrm{mHz}$ is shown in Fig. 4b. The wave shows some evidence of poleward phase propagation, and has an amplitude peak at the equatorward edge of the region of artificial scatter close to $65.6^{\circ}$ magnetic latitude. Only latitudes poleward of the resonance location are within the artificial scatter region, and this presumably precludes the observation of the full $180^{\circ}$ phase change expected around resonance (e.g. Walker et al., 1979). Figure 4c illustrates a velocity hodogram formed from merging 1-o-s velocities from the Hankasalmi and Pykkvibær radars. An elliptical, anticlockwise polarisation is seen (note that in this case the hodogram is for a later period of similar wave activity to Interval 1 , for which data was avail- 


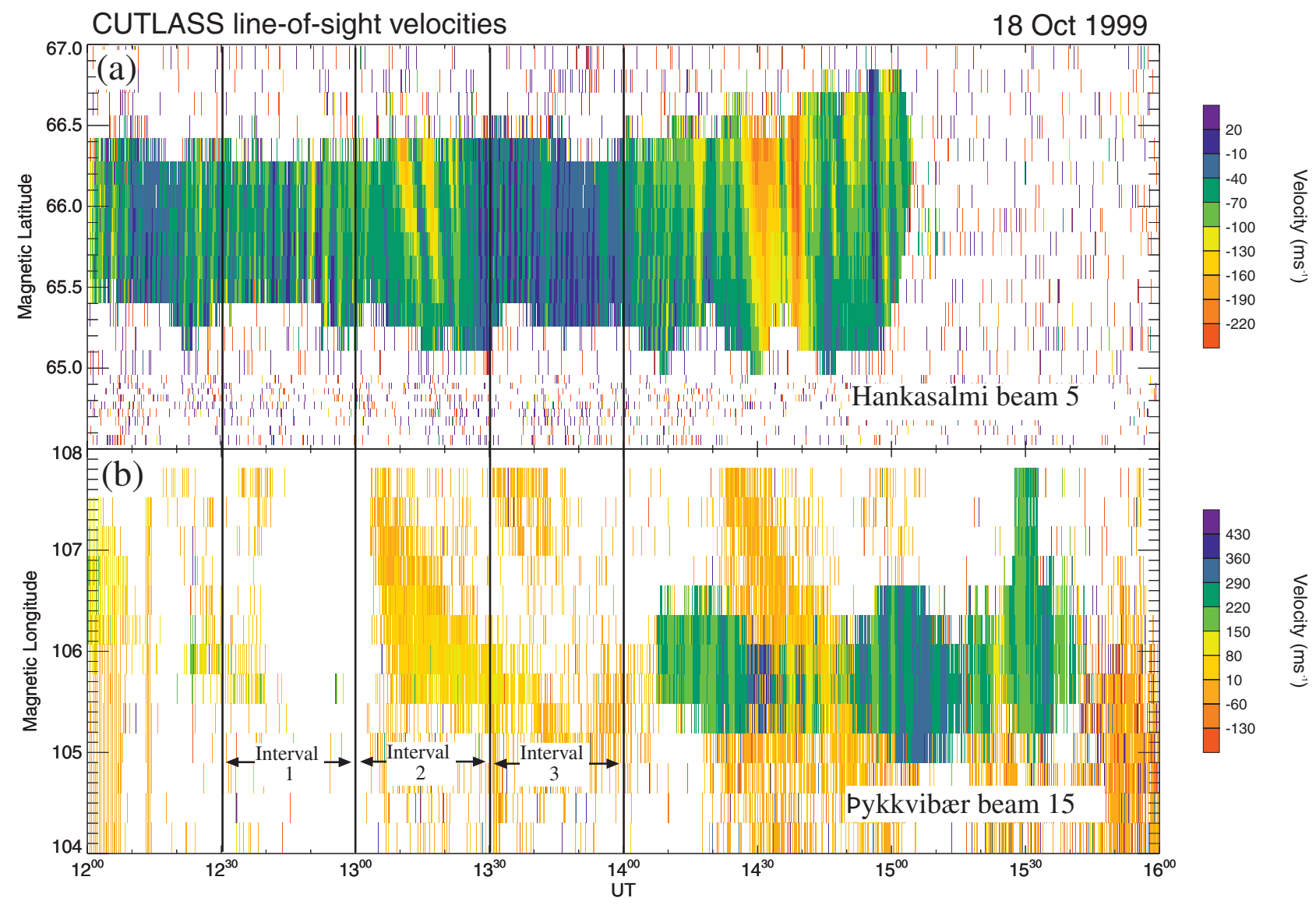

Fig. 2. An overview of the CUTLASS 1-o-s velocity data for the run of the SP-UK-OUCH from 1200-1600 UT on 18 October, 1999. (a) Beam 5 velocities from Hankasalmi, Finland as a function of geomagnetic latitude. (b) Beam 15 velocities from Pykkvibær, Iceland as a function of geomagnetic longitude. The velocities are colour-coded such that flow away from the radar (negative velocities) are indicated in red and flow toward the radar (positive velocities) are indicated in blue. The three intervals of data which will be examined further are indicated with solid vertical lines.

able from both Hankasalmi and Pykkvibær). A comparison of beams 4 and 5 of the Hankasalmi radar, and azimuthally separated stations of the IMAGE magnetometer array reveals that the wave has an azimuthal wavenumber, $m=+6 \pm 3$, i.e. an eastward phase propagation, in the direction of the solar wind flow. This wave is interpreted as a fundamental, large-scale toroidal field line resonance centred near $65.6^{\circ}$ magnetic latitude. The smaller wave at $16 \mathrm{mHz}$ has a similar low $m$-number and is interpreted as a harmonic of the 5.7 $\mathrm{mHz}$ large-scale toroidal wave. This smaller amplitude wave is not detected by the ground magnetometer at Troms $\emptyset$.

\subsection{Interval 2: 1300-1330 UT}

Interval 2 is presented in the same format as Interval 1 in Figs. 5 and 6, covering 1300-1330 UT. The wave in Interval 2 shows a clear equatorward phase propagation (Fig. 5a, b). It is only very weakly present in the Troms $\emptyset$ magnetometer records (Fig. 5c, d). The characteristics of the wave in the radar data are examined in detail in Fig. 6. The Fourier power spectrum in Fig. 6a shows a dominant frequency in this interval of $3.8 \mathrm{mHz}$. The magnetic latitude profile of
Fourier power and phase between $2.8-3.8 \mathrm{mHz}$ (Fig. 6b) confirms the strong equatorward phase propagation, and the wave can be seen to have a maximum amplitude at or above the poleward edge of the region of artificial backscatter at $66.0^{\circ}$ magnetic latitude. A comparison of beams 4 and 5 of the Hankasalmi radar reveals an azimuthal wavenumber, $m=-35 \pm 6$. The wave thus has an effective azimuthal wavenumber much larger than the Interval 1 wave, and propagates westward in a direction opposite to the solar wind flow, but in the direction of gradient-curvature drifting protons. The merged velocity hodogram from a subset of Interval 2 in Fig. 6c shows the wave to have a more linear polarisation than the large scale waves similar to those examined in Interval 1, but again have anticlockwise polarisation.

\subsection{Interval 3: 1330-1400 UT}

Interval 3 is again presented in the same format as Interval 1 and 2, in Figs. 7 and 8, covering 1330-1400 UT. The wave in Interval 3 shows a poleward phase propagation (Fig. $7 \mathrm{a}, \mathrm{b})$. It is not visible in the Troms $\emptyset$ magnetometer records (Fig. 7c, d). The characteristics of the wave in the radar 
Hankasalmi beam 5 I-o-s velocity

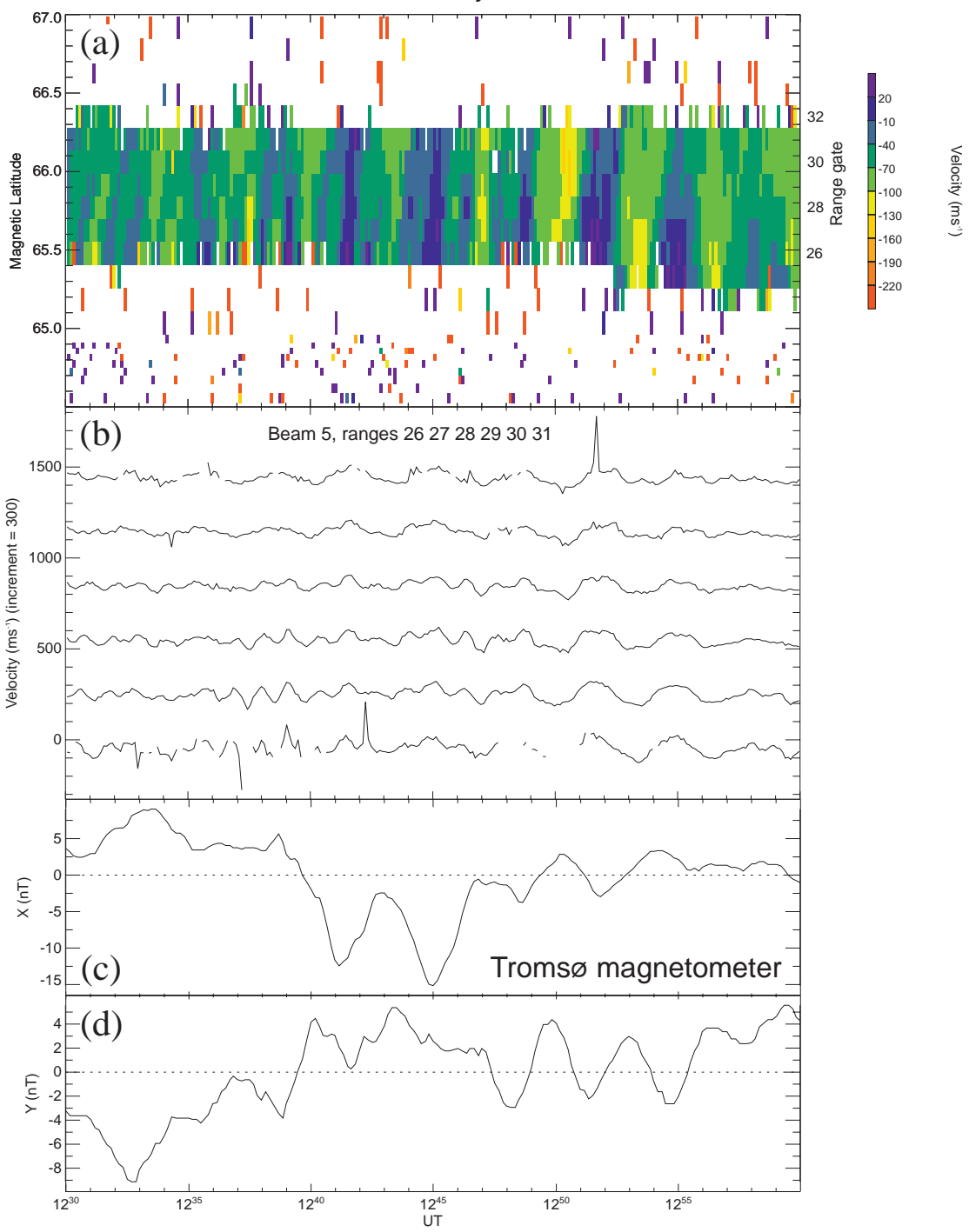

(a)

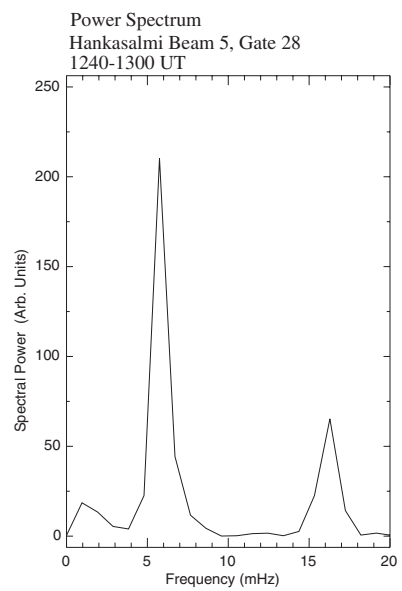

(b)

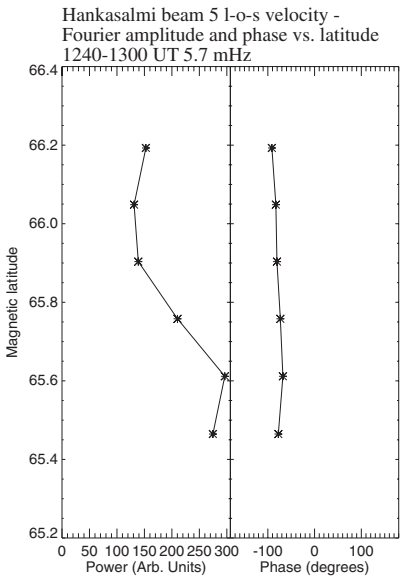

Fig. 3. Interval 1, 1230-1300 UT: (a) Beam 5 velocities from Hankasalmi, Finland as a function of geomagnetic latitude. The velocities are colourcoded such that flow away from the radar (negative velocities) are indicated in red and flow toward the radar (positive velocities) are indicated in blue. Radar range gate is also indicated on the right. (b) A timeseries representation of the velocity measurements in (a). (c) $\mathrm{X}$ and (d) $\mathrm{Y}$ component magnetograms from the TRO magnetometer. The magnetometer lies under range gate 32 . (c)

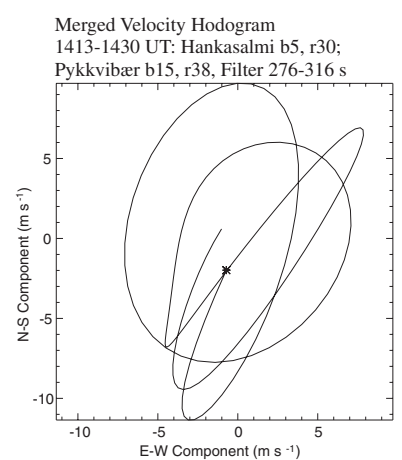

Fig. 4. Interval 1. (a) Fourier power spectrum, (b) magnetic latitude profile of Fourier power and phase, (c) merged velocity hodogram (note the hodogram is for a later period of similar wave activity to Interval 1, for which data was available from both Hankasalmi and Pykkvibær). 
Hankasalmi beam 5 I-o-s velocity

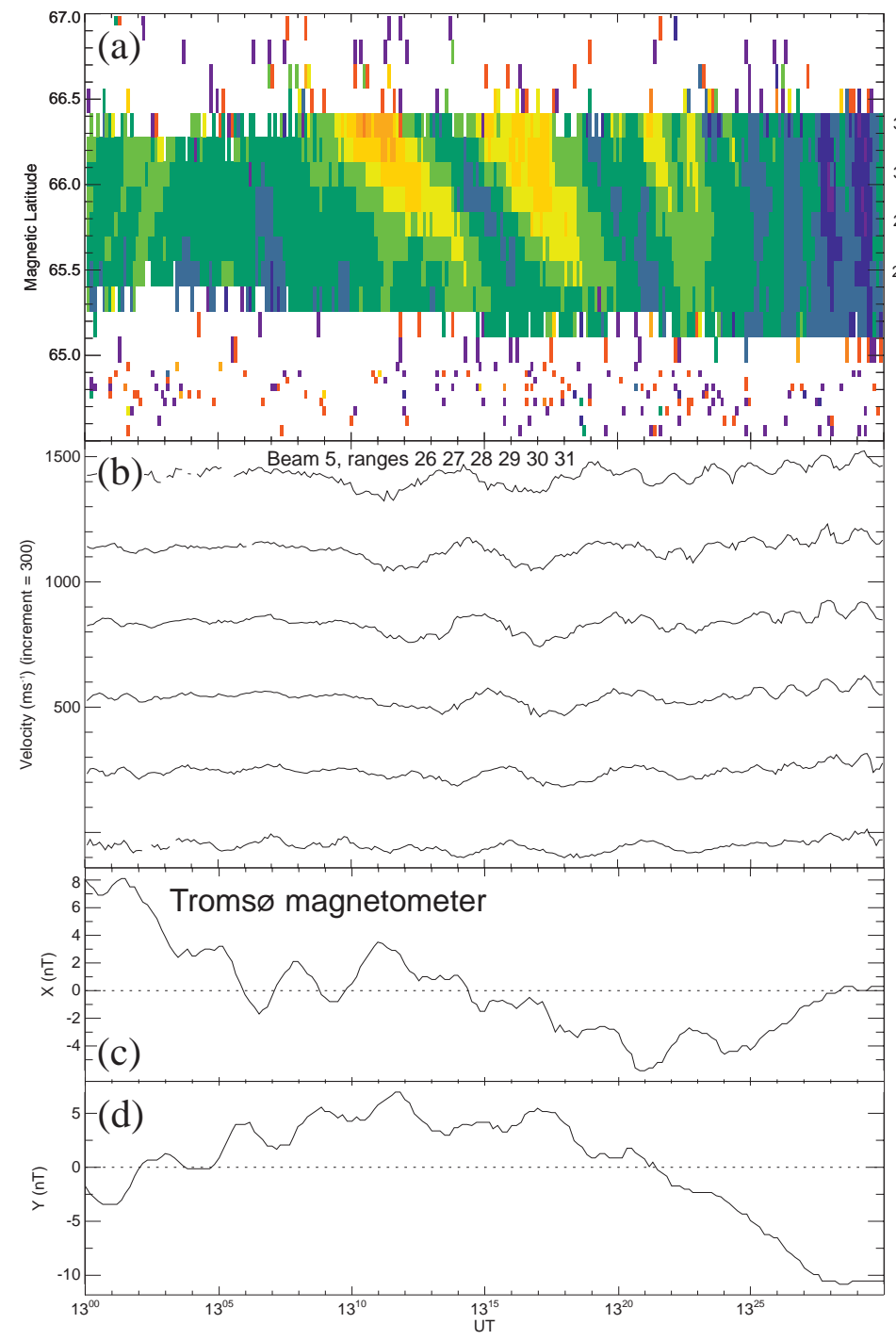

(a)

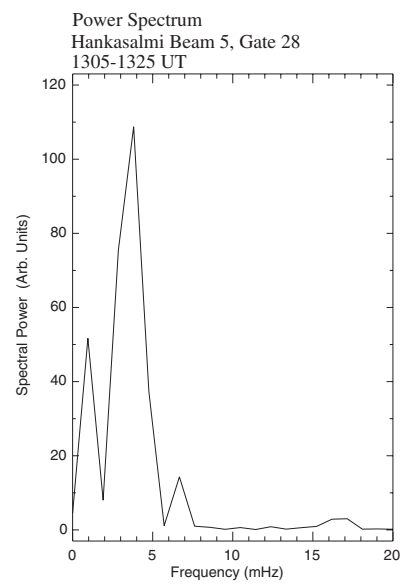

(b)

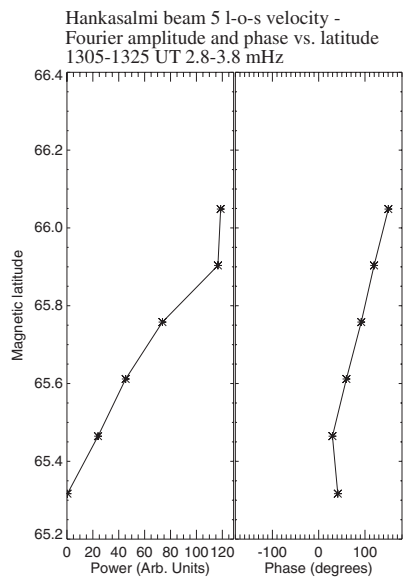

Fig. 5. Interval 2, 1300-1330 UT. Format as for Fig. 3. (c)

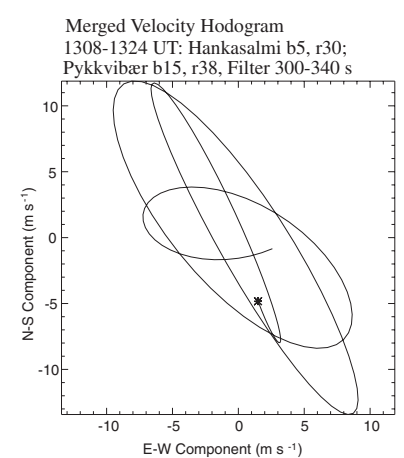

Fig. 6. Interval 2. (a) Fourier power spectrum, (b) magnetic latitude profile of Fourier power and phase, (c) merged velocity hodogram. 
Hankasalmi beam 5 I-o-s velocity

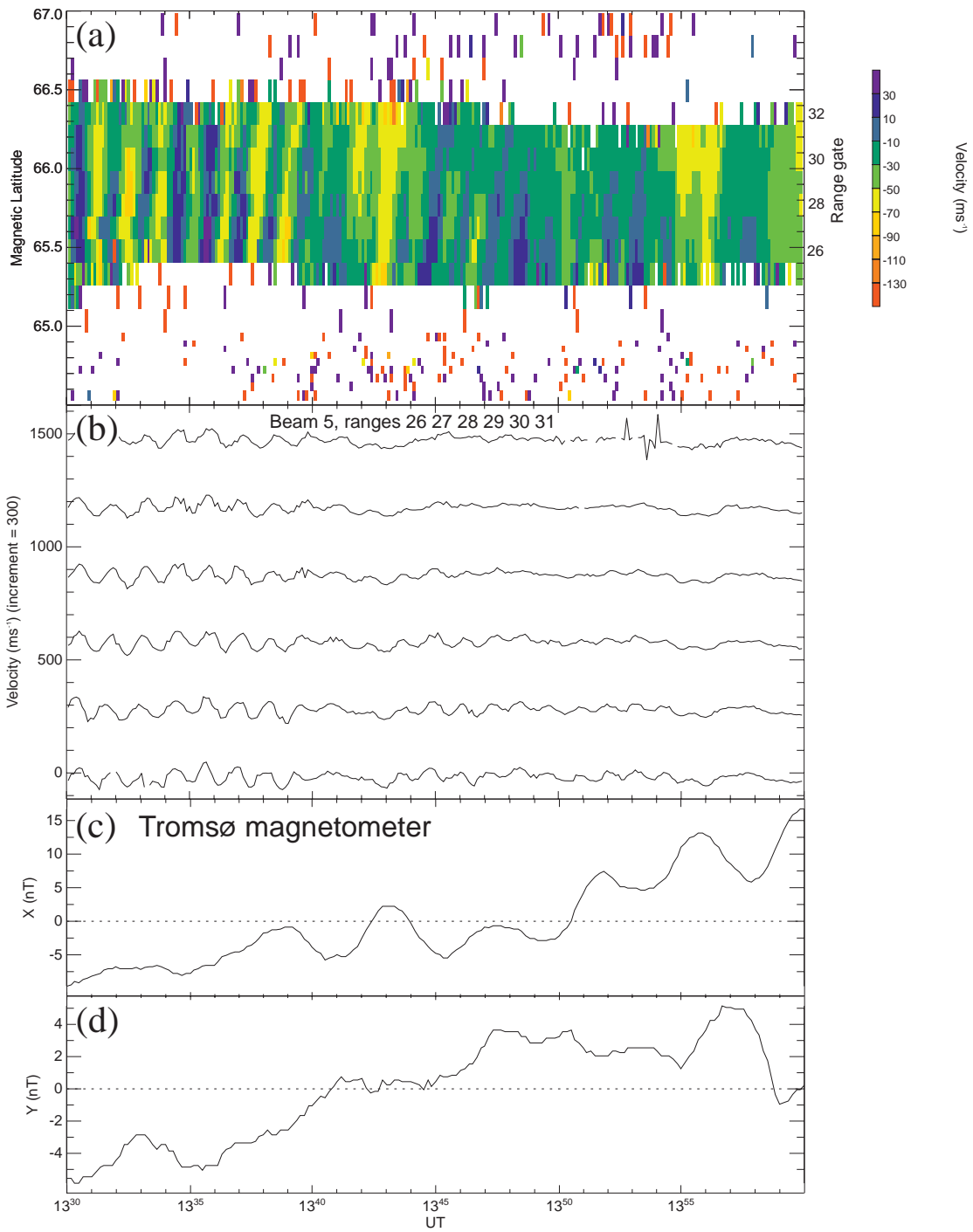

(a)

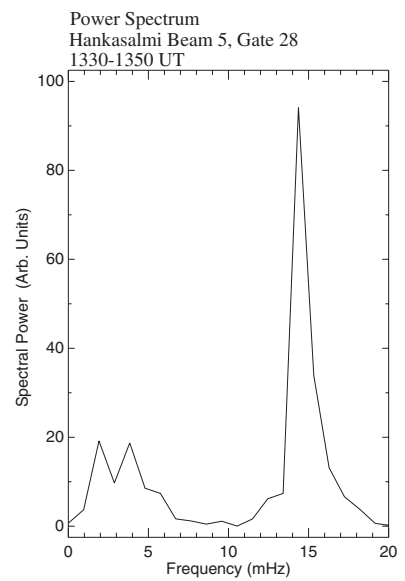

(b)

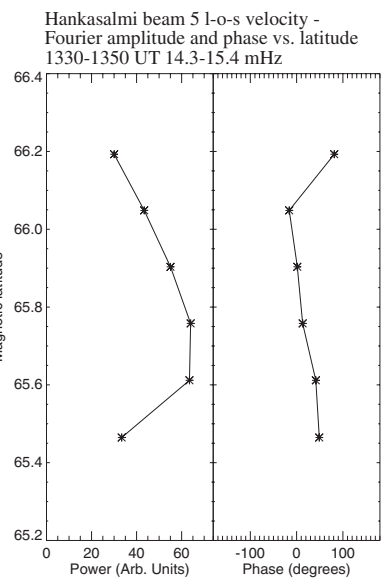

Fig. 7. Interval 3, 1330-1400 UT. Format as for Fig. 3 . (c)

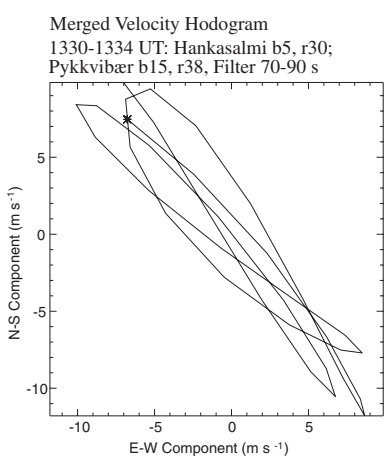

Fig. 8. Interval 3. (a) Fourier power spectrum, (b) magnetic latitude profile of Fourier power and phase, (c) merged velocity hodogram. 
Table 1. Summary of the ULF wave parameters and their interpretation in terms of wave energy source, for the three intervals under study

\begin{tabular}{lccc}
\hline & Interval 1 & Interval 2 & Interval 3 \\
\hline Frequency $(\mathrm{mHz})$ & 5.7 & 3.8 & 14.3 \\
$m$-number & $+6 \pm 3$ & $-35 \pm 6$ & $-35 \pm 6$ \\
$\begin{array}{l}\text { Large-scale } \\
\text { Interpretation }\end{array}$ & $\begin{array}{c}\text { Fundamental } \\
\text { poloidal drift } \\
\text { resonance }\end{array}$ & $\begin{array}{c}\text { Second harmonic } \\
\text { drift-bounce } \\
\text { resonance }\end{array}$ \\
$\begin{array}{l}\text { Inferred proton } \\
\text { energy (keV) }\end{array}$ & & $47 \pm 10$ & $34 \pm 10$ \\
\hline
\end{tabular}

data are examined in detail in Fig. 8. The Fourier power spectrum in Fig. 8a shows a dominant frequency in this interval of $14.3 \mathrm{mHz}$. The magnetic latitude profile of Fourier power and phase between $14.3-15.4 \mathrm{mHz}$ (Fig. 8b) confirms the poleward phase propagation, and the wave can be seen to have a maximum amplitude close to $65.7^{\circ}$ magnetic latitude. A comparison of beams 4 and 5 of the Hankasalmi radar again reveals an azimuthal wavenumber, $m=-35 \pm 6$. The wave thus has an effective azimuthal wavenumber much larger than the Interval 1 wave, but very similar to the wave in Interval 2, and again in a direction opposite to the solar wind flow, but in the direction of gradient-curvature drifting protons. The merged velocity hodogram from a subset of Interval 3 in Fig. 8c shows the wave to have a very linear polarisation.

\section{Discussion}

The artificial backscatter technique has provided an extended interval of very high resolution ionospheric velocity data, which has allowed the accurate characterisation of wave parameters such as frequency, latitudinal evolution of Fourier phase and amplitude, and wave polarisation within the ionosphere for 3 different, naturally-occurring ULF waves. These wave characteristics, described in Sect. 3, have revealed three very different wave types, occurring within 1.5 hours. Taken individually, each wave type would be difficult to interpret unambiguously. Here the three intervals will be considered in turn and in combination, in order to provide a convincing explanation of the complete interval. The wave parameters and interpretation for the three intervals are summarised in Table 1.

\subsection{Interval 1: large-scale field line resonance}

Interval 1 (Fig. 3) has a frequency of $5.7 \mathrm{mHz}$ and an azimuthal wavenumber, $m=+6$, indicating phase propagation in the solar wind flow direction. It is thus a large scale wave and as such, it is also observed by the IMAGE magnetometer at Troms $\varnothing$. This wave is interpreted as a fundamental, largescale toroidal field line resonance with an energy source external to the magnetosphere. The wave is not of great inter- est in itself, but in the interval under study it does provide an evaluation of the fundamental toroidal eigenfrequency of the field line at $65.6^{\circ}$ magnetic latitude, which provides an invaluable context for the very different wave types which follow directly after Interval 1 . In order to make predictions as to the frequencies of other possible wave modes in the artificial scatter, numerical solutions of the MHD equations for the ratios of toroidal and poloidal eigenfrequencies and harmonics for a dipole field at the latitude of geosynchronous orbit are employed (Cummings et al., 1969). Cummings and co-authors presented tabulated frequencies for the first 6 harmonics for radial plasma density models $r^{-n}$, where $0 \leq n \leq 6$. These predict that for a toroidal fundamental resonance frequency of $5.7 \mathrm{mHz}$ at $65.6^{\circ}$ magnetic latitude, the corresponding second and third harmonic frequencies lie between $11.8-15.3 \mathrm{mHz}$ and $17.5-24.6 \mathrm{mHz}$, respectively, for both the toroidal and poloidal mode (the range of values being a function of the plasma density model adopted). The fundamental poloidal frequency at this latitude is calculated to be $4.2 \mathrm{mHz}$ (this value is insensitive to the plasma density model). A correction of $\sim 10 \%$ would apply for resonances occurring at the poleward edge of the artificial scatter region due to the longer field lines connecting to this region (Mathie et al., 1999) and thus, leading to a predicted poloidal eigenfrequency in that location of $3.8 \mathrm{mHz}$.

\subsection{Interval 2: drift resonance}

Interval 2 (Fig. 5) has a wave with a frequency of $3.8 \mathrm{mHz}$ and an azimuthal wavenumber $m=-35$, and shows clear equatorward phase motion. The wave thus has azimuthal phase propagation opposite to the solar wind flow, but in the direction of gradient-curvature drifting protons. The frequency of this wave lies in the region expected for the fundamental poloidal mode, as deduced in Sect. 4.1. The fundamental poloidal wave is thought to be driven by drift resonance with westward moving, large pitch angle protons as suggested by Southwood and Kivelson (1982), and illustrated schematically in Fig. 9a. Interaction with the fundamental wave which has a symmetrical electric field is probably the only viable mode for drift resonance. The interaction will be strongest for large pitch angle protons which are confined near the equator where the wave electric field is strongest. 
(a)

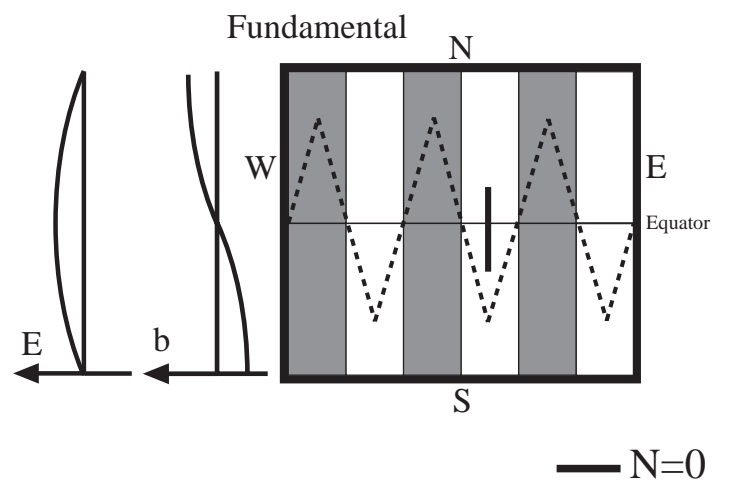

(b)

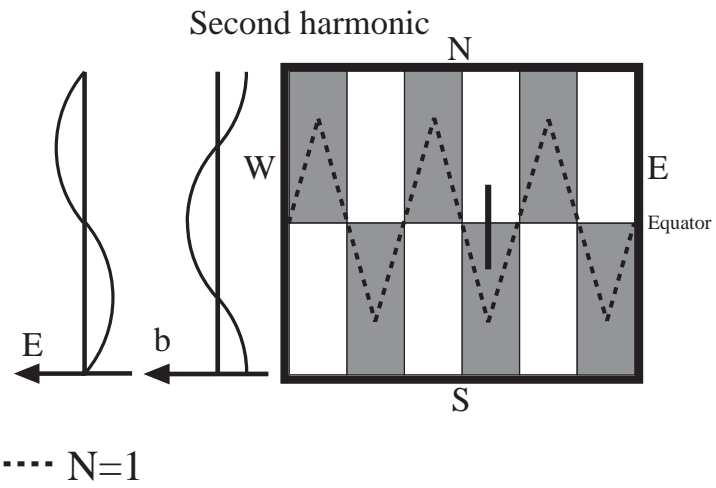

Fig. 9. Trajectories of two ions (solid and dashed lines) in the wave rest frame. Shaded and unshaded regions represent positive and negative electric field respectively. The ions indicated with a solid line are in resonance with the $N=0$ drift mode, and the ions represented by the dashed line with the $N=1$ drift-bounce resonance (after Southwood and Kivelson, 1982).

Using the drift resonance equation (e.g. Hughes, 1983) the angular frequencies of the azimuthal evolution of the wave, $\omega_{\text {wave }}$ and particles, $\omega_{\text {drift }}$ may be related by

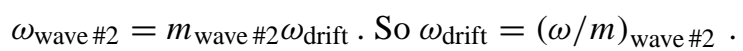

This gives a value for $\omega_{\text {drift }}$ of $6.8 \cdot 10^{-4} \mathrm{rad} \mathrm{s}^{-1}$. An expression of the angular frequency of drifting protons in the Earth's reference frame as a function of proton energy has been given by Chisham (1996) as

$$
\begin{aligned}
\omega_{\mathrm{drift}}= & -\frac{6 W L(0.35+0.15 \sin \alpha)}{B_{S} R_{E}^{2}} \\
& +\frac{90\left(1-0.159 K_{p}+0.0093 K_{p}^{2}\right)^{-3} L^{3} \sin \phi}{B_{S} R_{E}^{2}},
\end{aligned}
$$

where $W$ is the proton energy in $\mathrm{eV}, L$ is the proton's $L$-shell, $B_{s}$ is the equatorial surface magnetic field strength, $R_{E}$ is the radius of the Earth, $\alpha$ is the proton equatorial pitch angle, $\phi$ the azimuth of the particle measured anticlockwise from local midnight and $K_{p}$ the planetary magnetic activity index. The first term on the right hand side of Eq. 3 represents gradient-curvature drift and the second $\boldsymbol{E} \times \boldsymbol{B}$ drift under a model magnetospheric potential. Where the actual magnetospheric electric field can be estimated from measured ionospheric electric fields from radar data, as in this example, the equation may be replaced with

$$
\omega_{\mathrm{drift}}=-\frac{6 W L(0.35+0.15 \sin \alpha)}{B_{S} R_{E}^{2}}+\frac{E L^{2}}{B_{S} R_{E}}
$$

(Chisham et al., 1992), where $E$ is the magnetospheric electric field. In the example presented here, Eqs. 3 and 4 give consistent results and suggest that the energy of drifting protons which might drive the Interval 2 wave via drift resonance is $47 \pm 10 \mathrm{keV}$ for large pitch angle protons.

\subsection{Interval 3: drift-bounce resonance}

Interval 3 (Fig. 7) has a wave with a frequency of $14.3 \mathrm{mHz}$ and an azimuthal wavenumber, $m=-35$. The wave thus has azimuthal phase propagation opposite to the solar wind flow, but in the direction of gradient-curvature drifting protons, as is the case for Interval 2. The frequency of this wave lies in the region expected for the second harmonic poloidal mode, as deduced in Sect. 4.1. The second harmonic poloidal wave is thought to be driven by drift-bounce resonance with westward moving, small pitch angle protons as suggested by Southwood and Kivelson (1982), and illustrated schematically in Fig. 9b. If a drifting energetic proton population is to provide an energy source for Interval 3, then it must be able to satisfy the drift-bounce resonance condition, Eq. 1. This condition can only be met for $N= \pm 1$ for wave modes with antisymmetric electric fields. The interaction will be the strongest for particles of smaller pitch angles, which spend appreciable amounts of time near the wave electric field antinodes.

The drift angular frequencies for particles with small pitch angles can again be evaluated as a function of particle energy using Eqs. (3) or (4). The bounce angular frequencies for such particles are given by

$\omega_{b}=\frac{\pi \sqrt{W}}{\sqrt{2 m_{p}} L R_{E}(1.3-0.56 \sin \alpha)}$

(Glassmeier et al., 1999; Schulz and Lanzerotti, 1974), where $m_{p}$ is the proton mass. Substituting these values into Eq. (1) for $N=+1$ yields a quadratic equation in $\sqrt{W}$. Solution of this quadratic yields a proton energy of $34 \pm 10 \mathrm{keV}$ for small pitch angle particles. Substitution back into Eqs. (2) and (4) gives a value for the drift and bounce angular frequencies of $\omega_{\text {drift }}=4.6 \pm 0.9 \cdot 10^{-4} \mathrm{rad} \mathrm{s}^{-1}$ and $\omega_{b}=0.09 \pm 0.02 \mathrm{rad}$ $\mathrm{s}^{-1}$, respectively. In fact, using Eqs. 3 or 4 for the protons of $47 \mathrm{keV}$ associated with Interval 2, but with small pitch angles, gives a slightly reduced angular frequency of $\omega_{\text {drift }}=5.5 \cdot 10^{-4} \mathrm{rad} \mathrm{s}^{-1}$ (compared to the $6.8 \cdot 10^{-4} \mathrm{rad}$ $\mathrm{s}^{-1}$ deduced from Eq. 2 above for interval 2). Thus, we conclude that we need a positive slope in the proton distribution function in the region $35-45 \mathrm{keV}$ to explain the observed 
wave behaviours in both Interval 2 and Interval 3. Furthermore, the pitch angle dependence of the drift period of the protons is consistent with the arrival of large pitch angle particles slightly in advance of smaller pitch angle particles, and thus the driving of the drift mode (Interval 2) slightly before the drift-bounce mode (Interval 3), as is observed.

\subsection{Relationship with previous observations}

Of the previously reported ground-based observations of ULF waves, the waves identified in Intervals 2 and 3 of the reported run of the SP-UK-OUCH experiment most closely resemble those identified in naturally occurring coherent radar backscatter. The spatial resolution of such radars is $\sim 15 \mathrm{~km}$ and thus these instruments are much more sensitive to smallscale waves than ground magnetometers. Such small-scale waves observed by coherent radar have previously been classified as storm-time Pc5s (Allan et al., 1982, 1983; Walker et al., 1982) and equatorward propagating Pc5s (Grant et al., 1992; Yeoman et al., 1992). Storm time Pc5 waves are thought to have an energy source in gradient-drifting energetic particles in the dusk sector during disturbed times, and are generally interpreted as examples of drift resonance, although Allan et al. (1983) pointed out that no one generation mechanism was able to explain all the observed wave characteristics. A similar interpretation was placed on the dusk sector equatorward propagating waves observed by Yeoman et al. (1992) and Grant et al. (1992). Gradient-curvature drift for protons with energies in the range $35-70 \mathrm{keV}$ were deduced to be the driving mechanism for the storm time Pc5 pulsations of Allan et al. (1982, 1983). Such particle populations are also consistent with the equatorward propagating Pc5 pulsations observed by Yeoman et al. (1992) and Grant et al. (1992). The wave observed here in Interval 2 is fully in accord with these observations and their interpretation, providing high time resolution bistatic data of an equatorward propagating drift wave in the dusk sector. The wave polarisation observed here was near-linear with the polarisation ellipse tilted north-west to south-east. This is also very similar to the bistatic radar results of Allan et al. (1982, 1983), Grant et al. (1992) and Walker et al. (1982). Walker et al. (1982) mapped such polarisation ellipses out into the equatorial plane magnetosphere and demonstrated that they were consistent with poloidal wave modes. In Intervals 2 and 3 the ULF waves had a weak or non-existent signature in ground magnetometer data, as small-scale waves suffer attenuation through the ionosphere. This is again consistent with previous results. Related spacecraft observations include those from Kokubun (1985), Anderson et al. (1990), Engebretson et al. (1992) and Lessard et al. (1999) who observed Pc5 band ULF waves in the magnetosphere which were most common at dusk and were most likely storm-time Pc5 pulsations. At lower occurrence rates, events have also been observed in the dawn region within the magnetosphere and their relative occurrences have been discussed by Yeoman et al. (2000).

The wave in Interval 3, in contrast, appears to result from a second harmonic due to bounce-resonance interactions. This wave resembles ground-based magnetometer observations of giant pulsations $(\mathrm{Pg})$ which have a similar $m$-number (Chisham and Orr, 1991). Pg events have also been observed by auroral radar (Chisham et al., 1992) and occur in the morning sector in the 02-07 MLT interval, peaking in the range 03-06 MLT. A drift-bounce resonance interaction with an antisymmetric wave mode in the quiet time ring current has been suggested as the likely mechanism causing this type of ULF wave (e.g. Chisham and Orr, 1991), although Pgs have also been related to drift-bounce resonance mechanisms with symmetric wave modes (e.g. Takahashi et al., 1992). Similar events in the morning sector, detected by DOPE, were reported by Yeoman et al. (2000). The spatial resolution of the DOPE sounder is $\sim 4 \mathrm{~km}$ (Wright et al., 1997) and thus it has the ability to detect ULF wave signatures with very small spatial scale sizes. These events were characterised by higher $m$-numbers $(\sim-90)$, and the wave particle interaction mode responsible for their generation is, as yet, unclear. Studies directed more towards the investigation of individual events have also provided related measurements from space, and a small number of direct measurements of $m$ in space have been reported as well. Hughes et al. (1979) described multiple satellite observations of a high frequency $(18.2 \mathrm{mHz}$ ) compressional wave at geostationary orbit in the dusk to midnight local time sector. The wave number $m$ was calculated to be -100 . Hughes et al. (1979) deduced that the wave was a second harmonic standing wave which led to their interpretation of the driving mechanism being a bounce resonance interaction with ring current protons of energy 1$10 \mathrm{keV}$. A similar interpretation was placed on a wave with a frequency of $5 \mathrm{mHz}$ and $|m| \sim 110$ in the postnoon sector studied by Takahashi et al. (1990). These events appear to be similar to the Interval 3 event identified here, although with a higher $m$-number.

Takahashi et al. (1985) made multi-spacecraft measurements of ULF waves in the frequency range $1-3 \mathrm{mHz}$. These workers were able to directly measure the azimuthal wavenumbers in the magnetosphere for a number of wave events, finding $m=-40 \ldots-120$, which is similar to those presented here. The distribution of such events found by Takahashi et al. (1985) was symmetrical about noon. Woch et al. (1990) presented a study of compressional events observed at geostationary orbit. Two populations of events were identified, one being a "diamagnetic" population, which occurred during an increase in the measured ion intensities, and was concentrated at the dusk sector. The second population was termed a "non-diamagnetic" population, which was not associated with recently injected particles, and was concentrated on the dawn flank. Both populations were interpreted as being antisymmetric modes.

The interval presented here demonstrates that the dusk sector is a region where drift resonance is a viable source of wave energy in the Pc5 band, as expected. What the data also demonstrates is that bounce-resonance interactions can also occur in the same region. The ground-based technique of artificial radar backscatter opens a new window on such 
events, and bounce-resonance waves in the postnoon sector with $m \sim-35$ are reported. It appears that a drifting particle population with a positive gradient in its proton distribution function can couple to ULF wave modes of both fundamental and second harmonic frequencies. The slower drifting larger pitch angle particles interact first with the fundamental, with the slightly delayed small pitch angle element of the population finding a preferred wave-particle interaction with the second harmonic slightly later on. Wright and Yeoman (1999a) presented an example of a high- $m$ wave in artificial backscatter which appeared to be a harmonic of a preexisting large-scale wave. They suggested that this might be an example of the seeding of high- $m$ waves by low- $m$ waves, as suggested by Allan and Wright (1997), although at a harmonic, rather than at the fundamental. The present observation strengthens this interpretation, with the low- $m$ wave coexisting with both fundamental and second harmonic high- $m$ modes. In addition, a mechanism for the evolution from the high- $m$ fundamental to the second harmonic has been suggested in the differential drift speeds of gradient-curvature particles of different pitch angles. The observation of both drift resonance and drift-bounce resonance interactions in the dusk sector has implications for the interpretation of the interactions responsible for previous and future observations of ULF waves driven by wave particle interactions in this sector. The dawn sector, in contrast, appears to be dominated by bounce-resonance interactions. Future observations will be able to determine if drift resonances are sustainable in the dawn region.

\section{Summary}

The artificial backscatter technique has provided an interval of bistatic ionospheric electric field data during a complex period of wave activity. Unprecedented spatial, temporal and electric field resolution is achieved. A large-scale (low- $m$ ) field line resonance is observed, and gives the fundamental toroidal eigenfrequency as $5.7 \mathrm{mHz}$. Subsequently, smallscale (high- $m$ ) particle-driven waves are also observed at frequencies of 3.8 and $14.3 \mathrm{mHz}$, near the expected frequencies of the fundamental and second harmonic poloidal modes, as deduced from the large-scale field line resonance observations. These two waves are consistent with a drift wave and a bounce-resonance energy source, respectively, with a driving particle population at $35-45 \mathrm{keV}$. It appears that the postnoon sector can support both drift resonance and drift-bounce resonance interactions for waves with $m \sim-35$.

Acknowledgements. The authors thank the director and staff of EISCAT for the operation of the Troms $\emptyset$ heater facility. EISCAT is an international facility funded collaboratively by the research councils of Finland (SA), France (CNRS), the Federal Republic of Germany (MPG), Japan (NIPR), Norway (NAVF), Sweden (NFR) and the United Kingdom (PPARC). The SuperDARN Hankasalmi and Pykkvibær HF radars are deployed and operated by the University of Leicester, and funded by the PPARC (Grant number PPA/R/R/ 1997/00256), the Finnish Meteorological Institute, and the Swedish
Institute for Space Physics. IMAGE data were kindly supplied by the Finnish Meteorological Institute. DMW is supported on PPARC Grant number PPA/G/O/1997/000254.

Topical Editor G. Chanteur thanks W. Allan and M. Hudson for their help in evaluating this paper.

\section{References}

Allan, W. and Wright, A. N., Large- $m$ waves generated by small- $m$ field line resonances via the nonlinear Kelvin-Helmholtz instability, J. Geophys. Res., 102, 19927, 1997.

Allan, W., Poulter, E. M., and Nielsen, E., STARE observations of a Pc5 pulsation with large azimuthal wave number, J. Geophys. Res., 87, 6163, 1982.

Allan, W., Poulter, E. M., and Nielsen, E., Pc5 pulsations associated with ring current proton drifts: STARE radar observations, Planet. Space Sci., 31, 1279, 1983.

Anderson, B. J., Engebretson, M. J., Rounds, S. P., Zanetti, L. J., and Potemra, T. A., A statistical study of Pc 3-5 pulsations observed by the AMPTE/CCE magnetic fields experiment. 1. Occurrence distributions, J. Geophys. Res., 95, 10495, 1990.

Bond, G. E., Robinson, T. R., Eglitis, P., Wright, D. M., Stocker, A. J., Reitveld, M. T., and Jones, T. B., Spatial observations by the CUTLASS coherent scatter radar of ionospheric modification by high power radio waves, Annales Geophysicae, 15, 1412, 1997.

Chisham, G., Giant pulsations: An explanation for their rarity and occurrence during geomagnetically quiet times, J. Geophys. Res., 101, 24755, 1996.

Chisham, G. and Orr, D., Statistical studies of giant pulsations (Pgs): harmonic mode, Planet. Space Sci., 39, 999, 1991.

Chisham, G., Orr, D., and Yeoman, T. K., Observations of a giant pulsation across an extended array of ground magnetometers and on auroral radar, Planet. Space Sci., 40, 953, 1992.

Cummings, W. D., O'Sullivan, R. J., and Coleman Jr., P. J., Standing Alfvén waves in the magnetosphere, J. Geophys. Res., 74, 778, 1969.

Eglitis, P., Robinson, T. R., Rietveld, M. T., Wright, D. M., and Bond, G. E., The phase speed of artificial irregularities observed by CUTLASS during HF modification of the auroral ionosphere, J. Geophys. Res., 103, 2253, 1998.

Engebretson, M. J., Murr, D. L., Erickson, K. N., Strangeway, R. J., Klumpar, D. M., Fuselier, S. A., Zanetti, L. J., and Potemra, T. A., The spatial extent of radial magnetic pulsation events observed in the dayside near synchronous orbit, J. Geophys. Res., 97, 13741, 1992.

Glassmeier, K.-H., Buchert, S., Motschmann, U., Korth, A., and Pedersen, A., Concerning the generation of geomagnetic giant pulsations by drift-bounce resonance ring current instabilities, Ann. Geophysicae, 17, 338, 1999.

Grant, I. F., McDiarmid, D. R., and. McNamara, A. G, A class of high- $m$ pulsations and its auroral radar signature, J. Geophys. Res., 97, 8439, 1992.

Greenwald, R. A., Weiss, W., Nielsen, E., and Thomson, N. P., STARE: A new radar auroral backscatter experiment in northern Scandinavia, Radio Sci., 13, 1021, 1978.

Greenwald, R. A. et al., DARN/SUPERDARN A global view of the dynamics of high- latitude convection, Space Sci. Rev., 71, 761, 1995.

Hughes, W. J., Hydromagnetic waves in the magnetosphere, Solar Terrestrial Physics (edited by R. L. Carovillano and J. M Forbes), Reidel, Dordrecht, 1983. 
Hughes, W. J. and Southwood, D. J., The screening of micropulsation signals by the atmosphere and ionosphere, J. Geophys. Res., 81, 3234, 1976.

Hughes, W. J., McPherron, R. L., Barfield, J. N., and Mauk, B. H., A compressional Pc4 pulsation observed by three satellites in geostationary orbit near local midnight, Planet. Space Sci., 27, 821,1979

Kokubun, S., Statistical characteristics of Pc5 waves at geostationary orbit, J. Geomag. Geoelectr., 37, 759, 1985.

Lessard, M. R., Hudson, M. K., and Lühr, H., A statistical study of Pc 3 - Pc 5 magnetic pulsations observed by the AMPTE/Ion Release Module satellite, J. Geophys. Res., 104, 4523, 1999.

Lühr, H., The IMAGE magnetometer network, STEP International Newsletter, 4, 4, 1994

Mathie, R. A., Menk, F. W., Mann, I. R., and Orr, D., Discrete field line resonances and the Alfvén continuum in the outer magnetosphere, Geophys. Res. Lett., 26, 659, 1999.

McNamara, A. G. , McDiarmid, D. R., Sofko, G. J., Koeler, J. A., Forsyth, P. A., and Moorcroft, D. R., BARS - a dual bistatic auroral radar system for the study of electric fields in the Canadian sector of the auroral zone, Adv. Space Res., 2, 145, 1983.

Nielsen, E., Guttler, W., Thomas, E. C., Stewart, C. P., Jones, T. B., and Hedburg, A., SABRE - new radar-auroral backscatter experiment, Nature, 304, 712, 1983.

Rietveld, M. T., Kohl, H., Kopka, H., and Stubbe, P., Introduction to ionospheric heating at Troms $\emptyset$ - I. Experimental overview, J. Atmos. Terr. Phys., 55, 577, 1993.

Robinson, T. R., The heating of the high latitude ionosphere by high power radio waves, Phys. Rep., 179, 79-209, 1989.

Robinson, T. R., Stocker, A. J., Bond, G. E., Eglitis, P., Wright, D. M., and Jones, T. B., O- and X-mode heating effects observed simultaneously with the CUTLASS and EISCAT radars and low power HF diagnostics at Troms $\varnothing$, Annales Geophysicae, 15, 134, 1997.

Robinson, T. R., Strangeway, R., Wright, D. M., Davies, J. A., Horne, R. B., Yeoman, T. K., Stocker, A. J., Lester, M., Rietveld, M. T., Mann, I. R., Carlson, C. W., and McFadden, J. P., FAST observations of ULF waves injected into the magnetosphere by means of modulated RF heating of the auroral electrojet, Geophys. Res. Lett., 27, 3165, 2000.

Schulz, M. and Lanzerotti, L. J., Particle diffusion in the radiation belts, Springer-Verlag, Berlin, Heidelberg, New York, 1974.

Southwood, D. J., A general approach to low-frequency instability in the ring current plasma, J. Geophys. Res., 81, 3340, 1976.
Southwood, D. J. and Kivelson, M. G., Charged particle behavior in low-frequency geomagnetic pulsations, 2. Graphical approach, J. Geophys. Res., 87, 1707, 1982.

Southwood, D. J., Dungey, J. W., and Etherington, R. J., Bounce resonant interactions between pulsations and trapped particles, Planet. Space Sci., 17, 349, 1969.

Takahashi, K., Higbie, P. R., and Baker, D. N, Characteristics of compressional Pc5 waves observed at geostationary orbit, J. Geophys. Res., 90, 1473, 1985.

Takahashi, K., McEntire. R. W., Lui, A. T. Y., and Potemra, T. A., Ion flux oscillations associated with a radially polarised transverse Pc5 magnetic pulsation, J. Geophys. Res., 95, 3717, 1990.

Takahashi, K., Sato, N., Warnecke, J., Lühr, H., Spence, H. E., and Tonegawa, Y., On the standing wave mode of giant pulsations, J. Geophys. Res., 97, 10,717, 1992.

Walker, A. D. M., Greenwald, R. A., Stuart, W. F., and Green, C. A., STARE auroral radar observations of Pc5 geomagnetic pulsations, J. Geophys. Res., 84, 3373, 1979.

Walker, A. D. M., Greenwald, R. A., Korth, A., and Kremser, G., STARE and GEOS-2 observations of a storm time Pc5 ULF pulsation, J. Geophys. Res., 87, 9135, 1982.

Woch, J., Kremser, G., and Korth, A., A comprehensive investigation of compressional ULF waves observed in the ring current, J. Geophys. Res., 95, 15113, 1990.

Wright, D. M. and Yeoman, T. K., CUTLASS observations of a high- $m$ ULF wave and its consequences for the DOPE HF Doppler sounder, Ann. Geophysicae, 17, 1493-1497, 1999a.

Wright, D. M. and Yeoman, T. K., High resolution bistatic radar observations of ULF waves in artificially generated backscatter, Geophys. Res. Lett., 26, 2825-2828, 1999b.

Wright, D. M., Yeoman, T. K., and Chapman, P. J., High-latitude HF Doppler observations of ULF waves: 1 . Waves with large spatial scale sizes, Ann. Geophysicae, 15, 1548, 1997.

Yeoman, T. K., Tian, M., Lester, M., and Jones, T. B., A study of Pc5 hydromagnetic waves with equatorward phase propagation, Planet. Space Sci., 40, 797, 1992.

Yeoman, T. K., Wright, D. M., Robinson, T. R., Davies, J. A., and Rietveld, M. T., High spatial and temporal resolution observations of an impulse-driven field line resonance in radar backscatter artificially generated with the Troms $\emptyset$ heater, Ann. Geophysicae, 15, 634, 1997

Yeoman, T. K., Wright, D. M., Chapman, P. J., and Stockton-Chalk, A. B., High-latitude observations of ULF waves with large azimuthal wavenumbers, J. Geophys. Res., 105, 5453-5462, 2000. 